\title{
Fatal Sulfasalazine-Induced Eosinophilic Myocarditis in a Patient with Periodic Fever Syndrome
}

\author{
Ivica Jeremic ${ }^{a, c}$ Nada Vujasinovic-Stupar ${ }^{a, c}$ Tatjana Terzic ${ }^{b, c}$ \\ Nemanja Damjanov ${ }^{a, c}$ Milos Nikolic ${ }^{c, d}$ Branka Bonaci-Nikolic ${ }^{c, e}$ \\ ${ }^{a}$ Institute of Rheumatology, ${ }^{b}$ Institute of Pathology, ${ }^{\mathrm{C}}$ Faculty of Medicine, University of Belgrade, and \\ Clinics of ${ }^{d}$ Dermatovenereology and ${ }^{e}$ Allergy and Clinical Immunology, Clinical Center of Serbia, Belgrade, Serbia
}

\section{Key Words}

Eosinophilic myocarditis - Drug-induced hypersensitivity syndrome · Sulfasalazine $\cdot$ Hyper-lgD syndrome · Periodic fever syndrome

\begin{abstract}
Objective: The aim of this paper is to report the first case of drug-induced eosinophilic myocarditis (EM) in a patient with hereditary periodic fever syndrome (PFS). Case: A 28-yearold man with hyper-IgD syndrome, one of the PFS, developed a sulfasalazine-induced systemic hypersensitivity reaction complicated by EM. Thirteen days after sulfasalazine introduction, which had been given for arthritis, the patient developed fever, facial/neck edema, rash and cardiogenic shock, and died within $8 \mathrm{~h}$. The autopsy revealed hemophagocytosis, while acute heart failure caused by necrotizing EM was established as the cause of death. Conclusion: This was a case of drug-induced EM in a patient with PFS that had an atypical presentation, rapid evolution and poor outcome.

(c) 2014 S. Karger AG, Basel
\end{abstract}

\section{Introduction}

Drug-induced hypersensitivity syndrome (DIHS), also known as drug rash with eosinophilia and systemic symptoms - DRESS - syndrome, is a rare ( $1 / 1,000-10,000$ exposures) but potentially fatal (10\%) systemic reaction, which occurs 1-8 weeks after exposure to anticonvulsants, sulfasalazine, allopurinol or antiretrovirals, etc. [1]. DIHS typically manifests with a rash and hepatic dysfunction, but may include nephritis, pneumonitis and rarely hemophagocytosis and eosinophilic myocarditis (EM) [1]. Hyper-IgD syndrome, one of the genetically defined periodic fever syndromes (PFS), also known as autoinflammatory syndromes, is characterized by reduced activity of mevalonate kinase and lifelong recurrent febrile attacks of a noninfectious origin [2]. It is not known how exactly a reduced activity of mevalonate kinase leads to PFS, but it has been reported that proinflammatory cytokine production in patients with hyper-IgD syndrome is strongly enhanced [3]. We hereby report a case of DIHS in a patient with PFS.

\begin{tabular}{ll}
\hline KARGER 125/s & $\begin{array}{l}\text { ○ 2014 S. Karger AG, Basel } \\
1011-7571 / 14 / 0242-0195 \$ 39.50 / 0 \quad \text { Karger }\end{array}$ \\
E-Mail karger@karger.com & $\begin{array}{l}\text { Thisis an Open Access article licensed under the terms of the } \\
\text { Creative Commons Attribution-NonCommercial 3.0 Un- } \\
\text { ported license (CC BY-NC) (www.karger.com/OA-license), } \\
\text { applicable to the online version of the article only. Distribu- } \\
\text { tion permitted for non-commercial purposes only. }\end{array}$
\end{tabular}

Ivica Jeremic, $\mathrm{MD}, \mathrm{PhD}$

Institute of Rheumatology

Resavska 69

RS-11000 Belgrade (Serbia)

E-Mail ivicaje@yahoo.com 
Fig. 1. a Heart histopathology: interstitial inflammation, focal necrosis (arrow) and disarray of myocardial cells. Hematoxylin and eosin stain. $\times 100$. b Heart histopathology: perivascular infiltrates of eosinophils and mononuclear cells (arrow), and some myocardial cells in disarray, undergoing necrosis. Hematoxylin and eosin stain. $\times 400$. c Lung histopathology: vascular congestion of alveolar wall capillaries (arrow) and alveolar damage. d Bone marrow: prominent active hemophagocytic CD68positive macrophages. CD68 immunoperoxidase staining. $\times 1,000$.
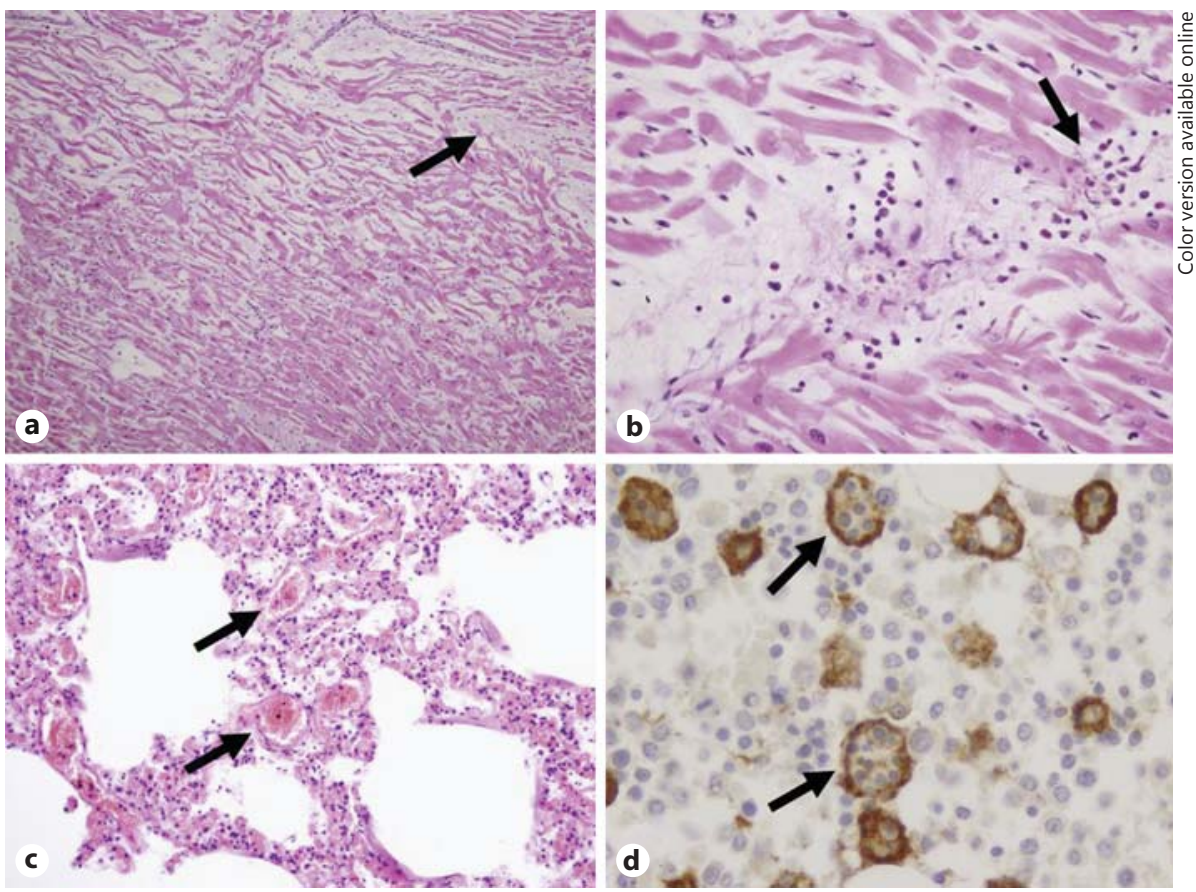

\section{Case Report}

A 28-year-old man presented to the Emergency Department of the Clinical Center of Serbia, Belgrade, with fever of $39.9^{\circ} \mathrm{C}$, facial/ neck edema, erythematous rash, cervical lymphadenopathy, malaise and shortness of breath that had commenced $24 \mathrm{~h}$ previously. He was tachycardic with a gallop rhythm, had dull heart sounds, and was tachypneic (20/min) and hypotensive (60/10 $\mathrm{mm} \mathrm{Hg})$. No murmurs or rubs were present. An electrocardiogram showed sinus tachycardia (150/min) with occasional premature ventricular extrasystoles. The patients' personal history revealed PFS present since childhood. He had had febrile attacks once a month, accompanied with cervical lymphadenopathy, abdominal cramps and arthritis. His febrile attacks had been treated with nonsteroid anti-inflammatory drugs and short prednisone courses. Previous attacks had been associated with high inflammatory markers, anemia and mild hepatosplenomegaly. His heart function had always been normal. He had been treated with sulfasalazine (500 mg t.i.d.) for ankle joint arthritis 2 weeks before this latest admission.

On admission, blood tests revealed leukocytosis $18.4 \times 10^{9}$ (78\% neutrophils without eosinophilia and atypical lymphocytes) and the following elevated inflammatory markers: C-reactive protein (151 mg/l), ferritin $(19,455 \mu \mathrm{g} / \mathrm{l})$, creatine kinase (313 U/l), MB (muscle brain) creatine kinase isoenzyme $(81 \mathrm{U} / \mathrm{l})$, troponin $\mathrm{T}$ (1.6 $\mu \mathrm{g} / \mathrm{l})$, aspartate aminotransferase $(287 \mathrm{U} / \mathrm{l})$ and alanine aminotransferase $(238 \mathrm{U} / \mathrm{l})$. Metabolic acidosis $\left(\mathrm{HCO}_{3} 4.6 \mathrm{mmol} / \mathrm{l}, \mathrm{pH}\right.$ $7.16, \mathrm{pCO}_{2} 1.7 \mathrm{kPa}$ ) was present. Chest X-rays showed cardiac enlargement. Plasma $\mathrm{N}$-terminal pro-B-type natriuretic peptide was also elevated at $215 \mathrm{ng} / \mathrm{l}$ (normal is $<100 \mathrm{ng} / \mathrm{l}$ ).

A diagnosis of cardiogenic shock was made and therapy with oxygen, fluids, inotropic agents, methylprednisolone (120 mg i.v.) and antibiotics was initiated. Despite this treatment, the patient died $8 \mathrm{~h}$ after admission.
The autopsy revealed EM with prominent interstitial edema and inflammatory infiltrate composed of eosinophils and mononuclear cells (fig. 1a, b). Vascular congestion of alveolar wall capillaries and alveolar damage were present (fig. 1c). Eosinophilic infiltrates were found in the stomach and skeletal muscles, while massive hemophagocytosis was observed in bone marrow and lymph nodes (fig. 1d). Acute heart failure caused by EM followed by pulmonary edema was established as the cause of death. The diagnosis of DIHS was confirmed by the first 5 of the following 6 diagnostic criteria: (i) a maculopapular rash developing 2-6 weeks after starting new therapy, (ii) lymphadenopathy, (iii) fever $\left(>38^{\circ} \mathrm{C}\right.$ ), (iv) leukocytosis $>10 \times 10^{9} / 1$ (without atypical lymphocytes and eosinophilia but with prominent tissue eosinophilia), (v) hepatitis (alanine aminotransferase, ALT $>100 \mathrm{U} / \mathrm{ml}$ ) and (vi) human herpes virus 6 reactivation (not tested) [1]. Genetic testing results, which were received postmortem, showed two heterozygous mutations in the gene for mevalonate kinase in exone 11 (C.1129G > A leading to P.V377I) and exone 6 (C.564.G>A leading to P.W188X) localized on $12 \mathrm{q} 24.11$, thus confirming hyper-IgD syndrome as one of the genetically defined hereditary periodic fever syndromes.

\section{Discussion}

Our patient with PFS had a fulminant presentation of EM, with the first symptoms occurring 13 days after the drug introduction, with cardiogenic shock and fatal outcome in the next $24 \mathrm{~h}$. EM is an under-recognized manifestation of DIHS that may occur in an acute form or can lead to progressive heart failure $[4,5]$. Ampicillin, aro- 
matic anticonvulsants and allopurinol are most frequently responsible for cardiac involvement in DIHS [5]. Myocarditis associated with DIHS often occurs one to several months later and even after the offending drug has been discontinued [5]. Myocardial injury is mediated by toxic cationic proteins, oxygen metabolites and lipid mediators produced by eosinophils [5].

Acute necrotizing EM is a rare and severe complication of DIHS that usually presents with acute chest pain, ST-segment elevation and an increase in cardiac enzymes, frequently with rapid deterioration of systolic function and a mortality rate above 50\% [4]. Pericarditis and cardiac arrhythmias are also possible presentations [5]. In most cases the diagnosis is established on autopsy.

Necrotizing EM, presenting as acute myocardial infarction, has been described in a patient with ankylosing spondylitis 6 weeks after starting sulfasalazine therapy [6]. Due to the increase of IL-1 family cytokines in hyperIgD syndrome [3], our patient had the hyperacute course of DIHS.

The relationship between toxic, viral and immune mechanisms in DIHS remains unresolved. A role of viral reactivation (especially of human herpes virus 6 and cytomegalovirus) is well known [1]. In our patient, contribution of viral reactivation could not be excluded, considering the presence of mixed cellular heart infiltrate and hemophagocytosis. The reactivation of Epstein-Barr virus and hemophagocytosis associated with sulfasalazine treatment have both been described [7].

Variability in clinical and laboratory presentation and concomitant use of anti-inflammatory drugs may delay the diagnosis of DIHS in patients with PFS. No blood eosinophilia together with tissue eosinophilia, as found in our patient, has been previously described [4]. Therefore, the absence of blood eosinophilia does not rule out the diagnosis of drug-induced EM. A positive in vitro lymphocyte transformation test, which was not performed in our patient, may be helpful in the diagnosis of sulfasalazine-induced DIHS. After 6 days of culture, the lymphocyte transformation test measures drug-specific proliferation $\left({ }^{3} \mathrm{H}\right.$-thymidine incorporation $)$ in comparison with negative and positive controls [8].

The diagnosis of EM is based on clinical criteria including electrocardiography, echocardiography and cardiac enzymes. The diagnosis is confirmed by endomyocardial biopsy [5]. In subacute and chronic EM, intracardiac thrombi, endomyocardial fibrosis and restrictive cardiomyopathy can be found.

A prompt diagnosis, immediate withdrawal of the offending drug and immunosuppressant therapy may decrease mortality in drug-induced acute EM [1]. Highdose systemic corticosteroids $(1 \mathrm{~g} /$ day for 3 days with slow tapering), intravenous Ig therapy $(1 \mathrm{~g} / \mathrm{kg})$, mycophenolate mofetil (1.5 g b.i.d.), azathioprine, rituximab and cyclosporine are possible treatment modalities [5].

In conclusion, this was a case of drug-induced EM in a patient with PFS that had atypical presentation, rapid evolution and a poor outcome.

\section{Acknowledgements}

We would like to thank Marco Gattorno, Isabella Ceccherini and Gordana Susic for genetic testing. This work was supported, in part, by the Ministry of Education and Science of the Republic of Serbia, Grant No. 175065.

\section{Disclosure Statement}

The authors have no conflicts of interest to disclose.

\section{References}

1 Ushigome Y, Kano Y, Ishida T, et al: Shortand long-term outcomes of 34 patients with drug-induced hypersensitivity syndrome in a single institution. J Am Acad Dermatol 2013; 68:721-728.

2 Haas D, Hoffmann GF: Mevalonate kinase deficiencies: from mevalonic aciduria to hyperimmunoglobulinemia D syndrome. Orphanet J Rare Dis 2006;26:1-13.

3 Galeotti C, Meinzer U, Quartier P, et al: Efficacy of interleukin-1-targeting drugs in mev- alonate kinase deficiency. Rheumatology (Oxford) 2012;51:1855-1859.

$4 \mathrm{Al}$ Ali AM, Straatman LP, Allard MF, et al: Eosinophilic myocarditis: case series and review of literature. Can J Cardiol 2006;22: 1233-1237.

5 Bourgeois GP, Cafardi JA, Groysman V, et al: A review of DRESS-associated myocarditis. J Am Acad Dermatol 2012;66:e229-e236.

6 Daoulah A, Alqahtani AA, Ocheltree SR, et al: Acute myocardial infarction in a 56-year-old female patient treated with sulfasalazine. Am J Emerg Med 2012;30:638.e1-e3.

7 Komatsuda A, Okamoto Y, Hatakeyama T, et al: Sulfasalazine-induced hypersensitivity syndrome and hemophagocytic syndrome associated with reactivation of Epstein-Barr virus. Clin Rheumatol 2008;27:395-397.

8 Zawodniak A, Lochmatter P, Beeler A, et al: Cross-reactivity in drug hypersensitivity reactions to sulfasalazine and sulfamethoxazole. Int Arch Allergy Immunol 2010;153:152-156. 